\title{
К ВОПРОСУ О КОРРЕКЦИИ УСТАНОВКИ НА СТРЕСС
}

\author{
Сакварелидзе Р., Бжалава Т. (Центр исследования и коррекции \\ психологической установки, Тбилиси, Грузия) \\ sakramaz@yahoo.com \\ Utinlümgर्uir mú. ' 07.08.2019

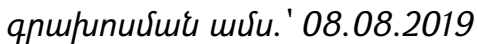

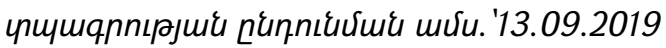

Исследование основывается на том предположении, что любое целостное состояние субъекта (установка) включает в себе программу модификации системы и возникает в ответ на восприятие чего либо. Практическое и теоретическое значение имеет замена программы стресса программой спокойствия и самоуверенности. Исследования эмоции, практика тренингов и теория установки подсказывают, что для коррекции установки на стресс целесообразно использовать не только релаксацию, но и установку на борьбу, самоуверенность, направление внимания на восприятие соответствующих частей собственного тела, в частности позвоночника.

Ключевые слова: стресс, установка, релаксачия, самоуверенность.

Проблема управления стрессом является актуальной, прежде всего, с практической точки зрения. Стресс ставит проблемы, ущерб от которых в некоторым странах измеряется миллиардами и поэтому, в любой сфере практики остро стоит необходимость преодоления стресса. Большую роль в этом играют психологические методы и факторы. Многие маститые учёные твердят, что нет ничего практичнее хорошей теории. Следовательно, стресс ставит задачи и перед психологическими теориями, хотя теориями упомянутая проблема не богата. Отдалённость академической психологии от проблемы стресса наверно, можно объяснить тем, что стресс от неё требует, как минимум, модель структурных (внутренних) механизмов функциональных психических и психофизиологических реакции человека, что, как известно, сделано не во всех парадигмальных теориях.

Ортодоксальный бихевиоризм вообще отвергал задачу моделирования внутренних механизмов. Психоанализ рассуждал лишь о механизмах структуры личности, хотя затрагивал многие аспекты стресса. Необихевиоризм ставил целью исследовать промежуточные переменные организма, разработал фррагменты отдельных переменных, важных и для стресса (навык, познание), но целостную модель всего механизма так и не создал. Перед необходимостью моделирования внутренних механизмов встал когнитивный поход, так как когниция компонент психического механизма. И как результат, этот подход породил ряд моделей эмоции, депрессии и стресса. Не умаляя значение этой продуктивной парадигмы, нельзя не отметить что и она порой фрагментарна. В этом подходе не всегда 
доработаны те фррагменты модели психических процессов, где присутствие познания не так ясна. Р. Лазарус, представитель когнитивной психологии, который внёс огромный вклад в «психологизации» теории стресса, ключевое значение придаёт оценку стрессора как опасности, а на других стадиях стресса психология у него отсутствует. Наверно, фрагментарностью модели обусловлено и то, что управление стрессом у Р. Лазаруса сводится лишь к коррекции оценки стимула пациентом. У него нет теории тех методов управления стрессом, которые на практике уже доказали свою эффрективность - существующие методы психотерапии, системы релаксации Джекобсона и Шульца, популярные на Западе разные варианты медитации заимствованные из йога или дзен, и т.д. Раз нельзя считать исчерпывающим когнитивную теорию стресса, ещё остаётся актуальным поиск более продуктивных подходов.

В этом поиске привлекает внимание теория Д. Узнадзе, так как центральное понятие его теории - установка, нацелено на объяснение внутреннего механизма психики. Теория эта опирается на обобщение фактов установки, которые отмечены психологами разных направлении. Считаем, что некоторые фракты заслуживают внимание теоретиков стресса. Установкой был назван в школе Кюльпе интроспективный фракт готовности, настроя (переживание, которое принимает в стрессе интенсивную форму). Установкой объяснил сам Кюльпе результаты опытов Л.Ланге, где направление внимания испытуемого на собственной руке сокращает время реакции (фиксация внимания на определённых участках тела характерно для интенсивной эмоции и стресса). Многие клинические психологи эфрфектом установки пациента считают эффекты плацебо/ноцебо или соматоморфные расстройства (аналогичные результаты даёт и стресс). Вообще, фактами разных психических, соматических и поведенческих эффектов установки богата практика внушения, особенно - гипнотического, установочный механизм которого выявил Д.Узнадзе (суггестия может стать причиной стресса, как показывают клиническая и социальная психология). Ригидностью установки объясняют ошибки в разных познавательных процессах, в том числе, в экспериментах грузинской школы (ригидность и деформация познания характерна и для стресса). Обобщая факты можно сказать, что восприятие информации создаёт (автоматический, неосознанно) установку на те изменения психических, соматических или поведенческих процессов личности, которые соответствуют семантике данной информации. Установка, как программа, управляет упомянутыми процессами. Между семантикой и установки связь до того тесная, что Узнадзе считал установку психическим эквивалентом значения предмета и знака (слова) [2]. В семантике информации заложена и программа более отдалённых будущих изменении, которые в соответствующих условиях автоматический делаются актуальными (один из примеров - постгипнотическое внушение). По Узнадзе есть разные формы установки: фиксированная - перешедшая в памяти; первичная - уникальная по 
мере уникальности ситуации; диффузная - неопределённая по деталям активности; диффференцированная - определённая по всем деталям.

Это описание фрактов установки в которых видно, что установка объясняет многие переживания, соматические и поведенческие процессы. Если постараться объяснить механизм формирования самой установки, то вслед за Ш.Чхартишвили [3] придётся допустить, что установку фрормируют предшествующие ей неосознанные когнитивные процессы (принятие информации, определение её семантики, определение связь между разными значениями, определение цели, будущей активности и нужных для её выполнения ресурсов) и на их основе создаётся программа будущих целостных изменении субъекта. Лишь после формирования такой программы может наступить готовность к целесообразному поведению. Мы считаем, что теоретический надо отделить установку неосознанно сфрормированную на начальном этапе, имеющую чисто психическую природу (условно обозначим её термином «установка-программа»), от установки следующего этапа, на котором создаётся психосоматическая по своей природе система актуальной готовности разных функции субъекта (условно назовём её «установкасостояние»). Без установки-программы не будет и установки-состояния, первая является системообразующим фактором второго. Часто эти два значения установки (программа и состояние) не дифференцируются, что может привести к недоразумениям. Например, в общей теории считается, что установка решает проблему взаимоотношения потребности субъекта и среды. Если установка состояние организма, не понятно как состояние может решать проблемы. Аналогично, фиксированные или дифференцированные формы не может иметь психосоматическое состояние. Эти недоразумения снимаются, если в этих контекстах подразумевать не состояние, а установку-программу. Есть и другой повод дифференциации этих фрорм установки - нельзя отожествлять системообразующий фактор с самой системой (в социально жизни правительство является системообразующим фрактором государства, но не является самим государством и их отожествление тоже приводит к недоразумениям).

По теории после формирования установки-состояния, она реализуется в активности. Если активность встречает препятствие, включаются эвристичные формы познания - инсайт у животного, сознательное мышление у человека. Узнадзе называет объективацией способность человека приостановить действие неосознанной установки и превратить ситуацию в объект сознательного познания. Такова, в общих чертах, модель психологического механизма активности по теории установки.

Описанная модель приложима ко многим проблемам психологии, в том числе к проблеме стресса и его преодоления. Во-первых, вспомним некоторые моменты классической модели стресса. Известно, что для Г.Селье стресс начинается с появления стимула, которого субъект считает сигналом опасности (стрессором). На 
первом этапе в субъекте происходит мобилизация его физических сил, что Селье назвал эустрессом, т.е. хорошим стрессом. Хороший стресс продолжается на этапе борьбы со стрессором. Селье отмечает, что если борьба безрезультативна, происходит биологическое истощение организма и наступает дистресс с негативными последствиями для организма, порой доходящими до гибели индивида. Причиной дистресса Селье считает истощение «адаптационной энергии», но не в состоянии определить природу этой энергии [1]. Получается, что у Селье дистресс, проблематичная форма стресса, фактически, остаётся без объяснения. Кроме этого модель дистресса по Селье имеет и другие недостатки, в частности, она не соответствует фактам. Достаточно привести один пример - в экспериментах Селигмана по выученной беспомощности, причиной дистресса был не расход энергии (он был выше у собак контрольной группы), а научение тому, что ситуация безысходна.

В грузинской психологической школе проблему стресса первым затронул М.Маградзе. Он отожествил стресс с установкой, но с установкой-состоянием, так как стресс тоже состояние. Эта позиция нам не кажется удовлетворительным. Во первых, установка участвует во многих процессах описанных выше, где нет стресса, т.е. эти два термина не идентичны. Во вторых, не даёт ничего нового рассмотрение двух терминов в качестве синонимов. В позиции Маградзе является спорным и то, что он не делает анализ дистресса, что сильно уменьшает практическую ценность его анализа.

Как многие исследователи, мы тоже считаем, что причина стресса не только в стрессоре. Да и сам стрессор воспринимается таковым, если семантика среды подразумевает угрозу, а семантика самого субъекта подразумевает, что эту угрозу он не преодолеет без напряжения сил (если он очень уверен в себе, даже мобилизация не происходит). В субъекте формируется программа мобилизации ресурсов, которая породит психосоматическое состояние мобилизации, что и является эустрессом. Но после того, как окажется, что активность блокируется и она безрезультативна, начинается, по Селье, фаза дистресса. В отличии от Г.Селье и Р.Лазаруса мы в формировании дисстресса усматриваем психологический механизм. Дистресс можно объяснить тем, что в результате поражения у субъекта формируется новая семантика самого себя - что он заблокирован, он не способен достичь свою цель. Эта семантика запускает программу блокировки возможностей и уже собственная программа мешает субъекту быть продуктивным, что служит причиной психических и соматических отклонении (которые встречаются при эффректов ноцебо, при фрустрации и негативных эмоциях, при психосоматических расстройствах и т.д.). Созданная под влиянием такой программы психосоматическая установка-состояние будет характеризоваться «истощением энергии", но не адаптационной, как у Селье, а психосоматической. Аналогичные явления происходят в опытах Селигмана когда у субъекта (собака, человек) в 
результате научения формируется семантика, что он беспомощен - он становится пассивным. Следовательно, мы считаем, что в формировании стадии стресса тоже действует механизм установки, который работает по принципу ассимиляции напряжённая ситуация вызывает состояние напряжения, блокирующая ситуация вызывает самоблокировку. Надо предполагать, что преодоление стресса будет возможно благодаря того-же установочного принципа ассимиляции.

Если сказанное правильно, то субъекту спокойствие должно принести спокойная ситуация. Известно, что многие копинг-стратегии направлены на включении субъекта в ту ситуацию, которая вызывает установку на спокойствие (отдых, музыка, компания друзей и т.д.). По аналогичному принципу действуют методы релаксации, медитации, восточных упражнении и др. В них создаётся физические и фризиологические условия для успокоения тела и вместе с этим предметов объективации становится тело, т.е. на нём направлено внимание. Спокойное тело порождает установку-программу на спокойствие, т.е. фрормируется программа уменьшения пульса, частоты дыхания, интенсивности психических процессов. Когда эта установка-программа хорошо зафиксирована в результате тренировок, человек легко может её актуализировать и по ней сформировать собственное состояние, противоположное стрессу. Так как спокойствие в данном случае достигается с помощью объективации тела, среда переходит на фон восприятия и теряет стрессогенную силу.

Если взять на вооружение принцип, что установка на спокойствие возникает под влиянием той информации, которая связана со спокойствием, можно сорормировать огромное количество методов преодоления стресса. Мы считаем перспективным развитие методов, где внимание направлено на те части тела, которые не участвуют в переживании интенсивной эмоции и стресса, они не вызовут установку на стресс (такие методы удобны и тем, что человек может ими пользоваться и при физической или психической активности). Финские психологи очень наглядно показали, что при интенсивных эмоциях интроцептивные ощущения имеют максимальную интенсивность в верхних частях тела (голова, грудь) и минимальную - в нижних частях (живот, ноги). Надо предполагать, что при стрессе минимальным должны быть ощущения и на спине, где порог ощущения самый высокий.

На основе сказанного мы апробировали систему коррекции установки на стресс, где внимание испытуемых концентрировалось на ногах и на спине, точнее на позвоночнике. Фиксация внимания на позвоночнике вызывает его выпрямление, а прямой позвоночник тесно связан с чувством самоуверенности в борьбе, что исключает чувство стрессовой беспомощности. Среди испытуемых, которые смогли преодолеть трудности интроспекции (её развитие требовало отдельные тренинги), до 70\% случаев у испытуемых после 3-4 занятии отмечалось уменьшение случаев дистресса, снятие напряжённости в мышцах тела и лица, 
освобождение дыхания, приподнятость настроения и т.д. Считаем, что результаты апробации указывают, что работа в этом направлении перспективна и должна продолжатся, тем более, что её поддерживает описанная выше теоретическая модель внутренних механизмов стресса.

\section{Литература}

1. Селье Г. Стресс без дистресса. Москва: Прогресс, 1979

2. Узнадзе Д.Н. Психологические исследования. Москва: Наука, 1966.

3. Чхартишвили Ш.Н. Некоторые спорные проблемы психологии установки. Тбилиси: Мецниереба, 1971.

\section{CORRECTION OF PSYCHOLOGICAL SET AS A RESPONSE TO STRESS}

Sakvarelidze R., Bzhalava T. (Psychological Set Research and Correction Center at Tbilisi State Medical University, Tbilisi, Georgia)

The study is based on the following assumption: Any integrated state of the subject (psychological set) involves a program for system modification and is formed as a response to the perception of this or that object /event. Replacement of the stress program with the placidity and self-confidence program is theoretically and practically important. Examination of emotions, training related experience and the theory of set imply that to correct set as a response to stressful experience it is advisable to use not only relaxation, but also the predisposition toward fight and self-confidence as well as focusing one's attention on the relevant parts of the body, particularly the spine.

Keywords: stress, relaxation, self-confidence, psychological set. 